\title{
Proceeding
}

Supplementary Issue: Winter Conferences of Sports Science. Costa Blanca Sports Science Events, 22-23 March 2021. Alicante, Spain.

\section{How to help foster teens form a positive self- concept in sports and exercise activities}

\author{
ALBINA R. DROZDIKOVA-ZARIPOVA $\triangle$, GULNARA F. BIKTAGIROVA, NIYAZ R. LATYPOV \\ Institute of Psychology and Education, Kazan (Volga region) Federal University, Russian Federation
}

\begin{abstract}
Purpose of the study: The purpose of the study is to develop and experimentally verify the psychological and pedagogical conditions for the formation of a positive self-concept for adolescents from a foster family as the foundation for their effective social adaptation and harmonious personal development. Methodology: Pedagogical experiment (stating, forming and control stages of the experiment) was chosen as the leading method of the study. It allowed to implement a set of developed psychological and pedagogical measures. The study featured 26 adolescents and 18 parents. Results: As part of the efforts invested, there was experimentally verified the effectiveness of the developed psychological and pedagogical conditions for the formation of a positive self-concept of adolescents from a foster family. There were also defined statistically significant positive changes in the indicators of self-concept components (cognitive, emotional-evaluative, and behavioural). Teenagers began to set more realistic goals, to adequately relate to their personal qualities, to their status among peers and in the family. There has been a positive tendency to accepting oneself as a holistic and consistent self-image, aligned with the ideal-self modality. Applications of this study: The results of the study can become an additional source for specifying modern theories of the formation of a positive self-concept, the developed programs can be used in the practice of social educators, educatorspsychologists working with foster children. Novelty/Originality of this study: The development of a methodological basis and effective psychological and pedagogical measures to form a positive self-concept for adolescents brought up in foster families is the scientific novelty of the study.

Keywords: Exercise activities; Self-concept; Components of self-concept; Adolescents; Foster families; Psychological and pedagogical conditions for the formation of a positive self-concept.

Cite this article as:

Drozdikova-Zaripova, A.R., Biktagirova, G.F., \& Latypov, N.R. (2021). How to help foster teens form a positive self-concept in sports and exercise activities. Journal of Human Sport and Exercise, 16(3proc), S1136-S1150. https://doi.org/10.14198/ihse.2021.16.Proc3.30
\end{abstract}

Corresponding author. Institute of Psychology and Education, Kazan (Volga region) Federal University, Russian Federation. E-mail: a.edumail@yahoo.com

Abstract submitted to: Winter Conferences of Sports Science. Costa Blanca Sports Science Events, 22-23 March 2021. Alicante, Spain.

JOURNAL OF HUMAN SPORT \& EXERCISE ISSN 1988-5202.

(c) Faculty of Education. University of Alicante.

doi:10.14198/jhse.2021.16.Proc3.30

S1136 | 2021| Proc3|VOLUME 16

(c) 2021 University of Alicante 


\section{INTRODUCTION}

\section{Relevance of the problem}

In adolescence, self-awareness undergoes fundamental changes, which play a key role in the formation of personality and determine its subsequent development. During this period of life, a teenager's attitude to the world and to him- or herself changes. It characterizes by a growing desire to self-actualize, to cognize his or her personal traits and qualities, and the person at that stage of development compares him- or herself with other people (Bozhovich, 2008; Bayanova et al., 2019; Podymov et al., 2019; Rassolov et al., 2020)), rethinking values, assimilating social norms and roles. Along with other factors it contributes to development of self-concept (Ananyev, 1980).

The positive self-concept largely determines the social adaptation of the teenager's personality, being also a regulator of their behaviour and activity (Remschmidt, 1994; Rean, Bordovskaya \& Rozum, 2002). The social environment, and above all, the family, is of paramount importance in the formation of the self-concept (Avdeev et al., 2019; Piralova et al., 2020; Gimaliev et al., 2020). The problem of the development of selfawareness and self-attitude of adolescents in the family and outside the family was raised by such scientists as A.M. Prikhozhan and N. N. Tolstoy (2007), G.Kh. Bagandova (2011), J.G. Barber and P.H. Delfabbro (2003), G.F. Biktagirova and R.A. Valeeva (2016). It is foster children who predominantly need focused help and support, they have great difficulty adapting to new conditions (Bolshakova, 2004), suffering from loss of control over their own lives (Oswald, Heil \& Goldbeck, 2009).

Therefore, the study of the self-concept of adolescents from foster families, besides being highly relevant, is also of great social significance.

\section{The degree of problem formedness}

Modern scientific studies of the national and foreign scholars are focused on the analysis of the content, structure, diagnostics, and factors of the self-concept development (Burns, 1982; Rogers, 1961; Cohn, 1984; Ivashchenko, Agapov, \& Baryshnikova, 2000).

Despite the polyvalence of viewpoints on the problem and the diversity of research in this field, the selfconcept belongs to the category with a fairly invariable status in the terminological system of modern science.

The recent scientific research approach self-concept as a unique "combination of self-perception, self-esteem and self-understanding of an individual. In other words, it is how this particular person sees himself, how he or she evaluates him- or herself and how he or she interprets his or her actions" (Sventsitsky, 2008). It is postulated to have multicomponent structure, including cognitive, emotional-evaluative, and behavioural components.

Recently, the theory and practice of psychological and pedagogical research have accumulated an extensive array of information that reveals the scientific foundations and specificity of adolescents' self-concept formation (Prokofieva et al., 2018; Khairullina et al., 2020).

An analysis of the recent years works shows that the vector of scientific research is aimed at studying the dynamics of the development of the self-concept in adolescence, investigating the features of the selfconcept formation for various categories of adolescents. 
As the research of N.I. Gutkina (1983) show, personal reflection is an important mechanism of selfawareness, it is a form of adolescent awareness of both his inner world and understanding of the inner world of other people.

Yu.N. Vladimirova (2007) states in one of her works that young adolescents go through the stage of active accumulation of self-beliefs associated with finding one's place in society as they need to be part of it. In general, younger adolescents are characterized by a positive self-esteem, a high level of emotional wellbeing and satisfaction in communication.

According to T.S. Butaryeva (2019), the vast majority of older adolescents self-assess themselves and their personal characteristics at a fairly high level, which indicates the formation of a positive self-attitude.

The works of foreign researchers are of particular interest in the framework of our study. So, C. Healy et al. (2019) verified experimentally that increasing self-esteem reduces the chances of teenage psychotic experiences.

A study by A. Kozina (2019) gives evidence that in the process of adolescent growing up, the emotional selfconcept decreases significantly, while general self-concept, as well as social self-concept and family selfconcept increase.

Scientists have found out that controlled negative life events reduce the initial life satisfaction of adolescents aged 12-19 years, while internal resources (self-efficacy) and family support increase initial life satisfaction. Over time, peer support, above all, helps mitigate the effects of controlled negative events on teenage satisfaction (Jhang, 2019).

The dissertation of E.V. Svistunova (2012) defines the features of self-concept of adolescents with behaviour disorder, translated into a decrease of self-esteem level and self-acceptance degree, as well as inadequacy and vague manifestation of personal identifications.

Recently, there have been efforts made to use active forms and techniques for development and formation of an adequate idea of their "self" in adolescents.

The efficiency of the development of a positively driven self-concept in young adolescents, according to T.L. Bogatyreva (2008), depends on regular training sessions in a specially organized adult environment of creative co-operation among peers and their self-expression in an atmosphere of acceptance of the personality of every participant.

A family is one of the most significant factors affecting the formation of self-esteem of adolescents. Our country in the last decade witnessed new options for placing children (family orphanages, foster homes, SOS villages, etc.), as a response to the increased number of orphans and children left without adult care. Families with adopted and foster children evolve to take a special place among the many family models.

Research by N.A. Vikdorova (2016) showed that the behaviour of adolescents in their foster families is characterized by a number of specific features, the most important of which are the desire to communicate with peers, to assert their self-consistency, independence, and personal autonomy. 
B. Fish \& B. Chapman (2004) emphasize that children in a foster home are prone to inadequate development because they are influenced by the high-risk environment and the self-employment before becoming part of the family.

Adolescents from foster families are not sufficiently involved in school activities and are more likely to demonstrate internalization symptoms, including depression, as well as symptoms associated with behaviour disorder (Wojciak, McWey and Helfrich, 2013).

E.A. Ovsyanikova (2018) obtained significant results in her study that reflect the specifics of self-awareness of modern adolescents brought up in foster families. It was found that foster adolescents are characterized by a rather high degree of self-concept development, the dominance of a desire to self-actualize, and interest in one's own personality in general. At the same time, adolescents from foster families are suspicious and distrustful; they have not yet developed a self-concept or self-image of themselves as individuals. In the process of self-actualization foster adolescents rely primarily on internal resources (on themselves).

According to O.A. Skorlupina (2015), adolescents from foster families are more likely to have internal conflict, closeness, low self-confidence, self-acceptance and self-worth, proneness to excessive self-indulgence and self-reflection, proceeding against the overall negative emotional background of self-attitude. In general, the self-attitude of adolescents from foster families is characterized by aggressive responses.

Despite a wide range of studies of the adolescents' self-concept, the formation of a positive self-concept of adolescents from the foster family has not yet been sufficiently studied.

\section{MATERIALS AND METHODS}

\section{Purpose of the study}

The purpose of this study is to develop and experimentally verify the effectiveness of psychological and pedagogical conditions for the formation of a positive self-concept for adolescents from a foster family.

\section{Research methods and techniques}

There was employed a set of mutually complementary methods to carry out the study: 1) theoretical (theoretical analysis of psychological and pedagogical literature, generalization of experience, classification, modelling); 2) empirical (pedagogical experiment, observation, testing, content analysis); 3) data processing methods (quantitative and qualitative analysis).

The following methods were employed in the course of the study:

- Diagnostics of Interpersonal Relationships methods (T. Leary), aimed at studying the subject's idea of him- or herself and the ideal "self" and the prevailing type of attitude to people, allowing us to study the cognitive component of the self-concept.

- The Who Am I Test (or Twenty Statements Test by M. Kuhn and T. McPartland modified by T.V. Rumyantseva), which allows to study the substantial characteristics of personality identity that reflect the cognitive component of the self-concept.

- Self-Concept Scale (E. Pearce, D. Harris), assessing the level and nature of development of selfconcepts for various subscales, corresponding to the emotional (scales: anxiety, confidence, happiness and satisfaction, appearance and physical attractiveness) and behavioural components of self-concepts (scales: communication, situation at school, position in the family, behaviour). 
- Dembo-Rubinstein Method modified by A.M. Prikhozhan and N. N. Tolstoy (2007), based on direct assessment (scaling) of a number of personal qualities by adolescents that determine the axiological component of the self-concept.

\section{Experimental base of the study}

Pilot testing was carried out on the premises of the State Budget Institution "Centre for Fostering Children without Parental Care, Training and Accompanying Foster Families in Kazan." In total, the study featured 26 adolescents, 16 girls and 10 boys (children's age was 12.9 with the range of \pm 1.8 years), as well as 18 parents.

\section{Experiment stages}

As part of this work, there was conducted a pedagogical sequential experiment aimed at creating a positive self-concept for adolescents from foster families. The experimental work was carried out during joint meetings on psychological follow-up, both with children and their foster parents.

The conducted pedagogical experiment was comprised of three stages:

1) at the ascertaining stage of the experiment according to the chosen methods there were defined the initial values of the studied indicators of the cognitive, emotional-evaluative, and behavioural components of the self-concept of adolescents brought up in a foster family.

2) at the formative stage of the experiment there were tested the psychological and pedagogical conditions for the formation of a positive self-concept in adolescents from a foster family;

3) at the control stage of the experiment, there was identified the dynamic pattern for the changes in the values of three components of the self-concept of the subjects. There was also tested the effectiveness of the developed psychological and pedagogical conditions. It implied defining the values of the studied indicators of adolescents following the selected methods for the ascertaining stage. As a result of qualitative and quantitative analysis using methods of mathematical statistics, we made conclusions about the effectiveness of the conditions used. The validity of the differences in the experimental data was assessed using the Wilcoxon T-test.

\section{RESULTS}

Testing the psychological and pedagogical conditions for the formation of a positive self-concept of adolescents from a foster family

A theoretical analysis of the research literature on the studied issues, as well as our practical experience, allowed us to distinguish the following set of psychological and pedagogical conditions for the formation of a positive self-concept of adolescents brought up in foster families:

1) assistance provided to a teenager in the process of self-actualization and self-acceptance by his or her keeping a personal diary "I Know Myself";

2) activities involving foster family to strengthen parent-child relationships using psychological and pedagogical methods and forms of interaction: conversations, exercises, role-playing games;

3) development and testing the "Happy Being Myself" program, which includes various methods of psychological and pedagogical interaction with adolescents.

It is assumed that adolescent keeps a diary of a free-style design and makes regular entries there for 4 months thereafter, making notes of weekly tasks completion: "Draw your portrait", "Write a wish list", etc. When performing the proposed tasks, the teenager creates drawings, collages and writes essays, etc. Tasks are given at the classes as part of the "Happy Being Myself" program and are carried out independently at 
home. Some of the tasks are performed together with parents at group classes. "I Know Myself' diary includes the following sections: "What Do I Know about Myself"; "Wish Board"; "I am in the Family"; "My Environment"; "The Shades of My Personality".

As part of the conditions provided for interaction with a foster family in order to strengthen parent-child relations, there has been developed a set of group classes for foster parents and their children that targets the following tasks: 1) family members unity; 2) harmonization of family relations; 3) development of communication skills of children and parents; 4) positive dynamics in parents' assessment of their relationship with children.

The set includes 4 training sessions for foster families, 60 minutes each, covering the following topics: "Feelings and Concerns", "Conflict"; "Mutual Understanding"; "Active Listening." The families were divided into three subgroups to conduct the classes.

There was organized a series of conversations with parents contributing to development of a positive selfconcept of adolescents from a foster family, featuring such topics as: "My Child Is a Teenager", "How to Understand a Teenager?" and etc.; joint parent-child discussions and discussions evolving around the question: "What difficulties have you encountered and what are the ways to address them?"

The purpose of the "Happy Being Myself" program is to promote the disclosure of the inner world of an adolescent, contribute to personal fulfilment.

The program is focused on solving the following tasks:

- Providing assistance to a teenager from a foster family in the process of his or her self-actualization, personal fulfilment and personality development, in taking responsibility for life choices, selfrealization, in expressing and accepting their feelings and emotions;

- Developing effective communication skills stemming from the understanding of their own experience and psychological principles of constructive communication.

The program consists of 17 lessons, including an introductory and final lesson, as well as three series comprising 5 lessons each.

1. "My Own Self" series. It will help to promote understanding and acceptance of themselves, their own personality. The following lessons are included: "Who Am I?", "I Love Myself!", "My Self-Esteem", "My Uniqueness", "My Qualities".

2. "My Emotions" series. The main goal is to contribute to the child's learning to explore their emotions in order to better understand themselves and others and correctly express their feelings; development of creative imagination, social cooperation and empathy. The series includes following classes: "What Is Good and What Is Bad?", "How to Control Yourself", "I Am not Afraid!", "Emotions in My Life", "Masquerade".

3. "Me and the Others" series. The psychological and pedagogical activity in this series is aimed at the formation of communicative skills of adolescents, as well as training adolescents from a foster family to listen to others, express and argue their point of view, training them to compromise and to resist manipulation. The following classes there have been developed for this series: "We Are Together!", "My Personal Opinion", "Let's Talk?", "How to Understand Other People?", "Learning to Speak". 
"Happy Being Myself" program used such forms and methods of psychological and pedagogical interaction as conversations, training sessions, exercises, discussions, methods of art therapy, game methods, etc.

Implementation conditions: the duration of the lesson is 60-90 minutes, organized weekly. The program was conducted in two subgroups of 13 people each.

\section{Research results}

The types of attitudes that adolescents from foster families have to others, following on Leary's method based analysis. The results obtained at the ascertaining and control stages of the experiment are presented in Table 1 and 2.

Table 1. Self-concept and ideal self-concept variables for adolescents from foster families (types of attitudes to others).

\begin{tabular}{lcccc}
\hline & \multicolumn{2}{c}{ Real-self } & \multicolumn{2}{c}{ Ideal-self } \\
\hline Types of attitudes to others & Ascertaining stage & Control stage & Ascertaining stage & Control stage \\
\hline Authoritarian & $10.8^{*}$ & $9.8^{*}$ & $11.9^{*}$ & $11.0^{*}$ \\
Self-centred & 9.5 & 9.2 & 8.8 & 8.0 \\
Aggressive & $8.4^{*}$ & $7.5^{*}$ & $8.1^{*}$ & $7.2^{*}$ \\
Suspicious & 7.8 & 7.6 & 5.5 & 5.3 \\
Submissive & 8.2 & 8 & 7.4 & 7.3 \\
Dependent & 9.4 & 8.8 & 8.2 & 8.0 \\
Friendly & $11.9^{* *}$ & $10.6^{* *}$ & $12.1^{*}$ & $11.2^{*}$ \\
Altruistic & $11.5^{*}$ & $10.5^{*}$ & $12.5^{* *}$ & $10.3^{* *}$ \\
\hline
\end{tabular}

Notes: ${ }^{*}$ - variation with $p \leq .05,{ }^{* *}$ - variation with $p \leq .01$.

Table 2. Main variables of "Dominance" and "Friendliness" for adolescents from foster families.

\begin{tabular}{lcccc}
\hline \multirow{2}{*}{ Variables } & \multicolumn{2}{c}{ Real-self } & \multicolumn{2}{c}{ Ideal-self } \\
\cline { 2 - 5 } & Ascertaining stage & Control stage & Ascertaining stage & Control stage \\
\hline Dominance & $5.26^{*}$ & $4.11^{*}$ & $10.17^{* *}$ & $7.2^{* *}$ \\
Friendliness & 6.02 & 6.95 & $8.83^{*}$ & $7.5^{*}$ \\
\hline
\end{tabular}

In accordance with the results obtained at the ascertaining stage, we can conclude that adolescents raised in foster families are characterized by both natural and imaginary hyper responsibility for themselves and others, excessively active attitude to others, perseverance in their desire to help; friendliness, the desire to be "good" for everyone without taking into account the situation, need of acceptance and social approval, emotional lability, expressiveness of the hysterical type of character; while demanding self-respect, a manifestation of dominance; with a pronounced self-esteem, with a tendency to have their own particular opinion, different from the opinions of others; in some specific situations, by demonstrating obedience and conformity to a given model of behaviour, by manifesting helplessness (the prevailing types of interpersonal relationships for the real-self-concept are "Authoritarian", "Egocentrical", "Dependent", "Friendly" and "Altruistic").

The subjects, viewing the concept of "ideal teenager," criticize their own qualities and want to be friendlier (12.1 points) and altruistic (12.5 points), i.e., strive for behaviour that basically verges on pathology. Subjects also tend to dominate, lead, and demonstrate a tendency to domineering tyrannical type of behaviour ("Authoritarian" variable - 11.9 points). 
As for ideal-self-concept, the other variables for adolescents raised in foster families have lower values compared to the variables of real-self one. The greatest discrepancy between the two modalities of selfidentifications was revealed in the "Suspicious" type (by 2.8 points), which testifies to the desire of adolescents to be less critical in relation to all social phenomena and people around them, and, above all, to foster parents. At the same time, adolescents tend to be more self-confident (the "Dependenf" type), more emotionally restrained, and openly express their own opinion (the "Subordinate" type).

In general, adolescents from foster families demonstrate a pronounced desire for leadership in communication, for dominance ("Dominance" variable), while they also seek to establish friendly relations and cooperate with others (indicator "Friendliness" variable) (see Table 2).

Ideally, according to the subjects, it is necessary to enhance the severity of these characteristics, with a prevalence of the desire for dominance, which, according to the degree of their manifestation, will correspond to radical behaviour.

At the control stage, a tendency to positive changes was found in the types studied. It was expressed in the manifestation of more adaptive behaviour in relationships with others, according to two modalities of the selfconcept.

Statistically significant shifts were identified in the following types: "Friendly", "Altruistic", "Authoritarian" and "Aggressive". Adolescents brought up in a foster family have a tendency toward persistence, perseverance, self-confidence, and a reduction of the conformal attitudes dominance.

Ideal self-concepts of adolescents are correlated for the same types of relationships with others.

In general, there is a harmonization of the relations of subjects with others, in the real-self and ideal-self modalities of adolescents brought up in foster families, with dominating desire to establish friendly relations and cooperate with others.

Using the "Who Am I?" method there were identified the substantive characteristics of self-concepts of adolescents from foster families, presented through self-description of identification characteristics at the ascertaining and control stages of the experiment (Table 3).

Table 3. Features of self-concept components of adolescents from foster families at the ascertaining and control stages of the experiment (\%).

\begin{tabular}{lcc}
\hline Self-concept features & Ascertaining stage & Control stage \\
\hline Reflective Self & 19.2 & 30.8 \\
Social Self & 26.9 & 26.9 \\
Communicative Self & 11.5 & 15.4 \\
Physical Self & 23.1 & 3.9 \\
Activity-focused Self & 11.5 & 11.5 \\
Future-focused Self & 7.8 & 11.5 \\
\hline
\end{tabular}

According to the content analysis of subjects' self-description, adolescents brought up in foster families at the ascertaining stage of the experiment chose primarily three indicators of identity: 1) Social Self (male/female student -69.1\%, "boy/girl" - 46\%, "friend/girlfriend" - 30.8\%, "son/daughter" - 26.9\%, etc.); 2) Physical Self, which includes statements about a subjective description of appearance and abnormal 
sensitivity ("sick", "attractive", "seems to be OK", "fat", "lanky") - 73\%, eating habits, pernicious habits (46\%); 3) reflective "self' includes personal identity (personal qualities ("good / kind", "spiteful" - 38.3\%), character traits ("I like to laugh / joke" - 54\%), personal characteristics (nicknames - 26. 9\%).

During the self-identification of adolescents at the control stage, quantitative and qualitative changes took place in such substantial characteristics as the Reflective Self, Communicative Self and the Future-focused Self. This redistribution of characteristics occurred as a result of a reduced self-description in the physical "self" category. The personal identity of adolescents is described, first of all, through personal qualities and character traits - 80.8\%, emotional attitude towards themselves ("I am "cool", "great guy") - 30.8\%; adolescents perceive themselves as a member of a group of friends $-73 \%$ and a subject of communication in general ("I like to communicate and make friends with people") - 30.8\%; The prospect of the future is represented, most often, through wishes, intentions and dreams related to family status (46\%), friends and communication (54\%), interests and hobbies (54\%), and professional sphere $(38.3 \%)$.

According to teenagers' evaluation of their self-identification characteristics at the ascertaining and control stages of the experiment, there were defined the dominant types of subjects by the degree of their emotional balance, reasonableness of their own attitude to emotionally significant events and phenomena (Table 4).

Table 4. Emotional balance degree of the adolescents from foster families (in percentage terms \% ).

\begin{tabular}{lcc}
\hline Types & Ascertaining stage & Control Stage \\
\hline Emotionally polar & 73.1 & 38.5 \\
Well-balanced & 15.4 & 57.7 \\
Hesitant & 11.5 & 3.8 \\
\hline
\end{tabular}

After the formative stage of the experiment, adolescents brought up in foster families have become more balanced and often maintain constructive relationships with other people, and above all, with foster parents and peers, resolving conflicts more quickly. They are more tolerant of other people's shortcomings and capable of managing stressful conditions.

Table 5. Indicators of the emotional component of the self-concept of foster adolescents at the ascertaining and control stages of the experiment (\%).

\begin{tabular}{|c|c|c|c|}
\hline Scales & Scale levels & Ascertaining stage & Control stage \\
\hline \multirow{3}{*}{ Appearance } & Low self-esteem & 11.5 & 3.9 \\
\hline & Moderate self-esteem & 54 & 57.9 \\
\hline & High self-esteem & 34.5 & 34.5 \\
\hline \multirow{3}{*}{ Anxiety $^{* *}$} & High level of emotional well-being & 38.3 & 50.2 \\
\hline & Moderate anxiety & 38.3 & 38.3 \\
\hline & High level of anxiety & 23.4 & 11.5 \\
\hline \multirow{3}{*}{ Happiness. Satisfaction* } & Feeling of discontent & 38.3 & 11.5 \\
\hline & Realistic attitude to life situation & 46.3 & 65.4 \\
\hline & Feeling satisfied with life & 15.4 & 23.1 \\
\hline \multirow{3}{*}{ Self-confidence* } & Lack of self-confidence & 30.8 & 15.4 \\
\hline & self-confidence & 54 & 76.8 \\
\hline & High level of self-confidence & 15.4 & 7.8 \\
\hline
\end{tabular}

Notes: * variation with $p \leq .05$. 
Changing attitudes and developing new patterns of subjects' behaviour became possible by increasing the adequacy of value judgments, stabilizing emotional states (reducing the emotionally polar type by $34.6 \%$ ); confidence in decision-making (decrease in the numbers of hesitant type by $7.7 \%$ ).

The results of the emotional component of the self-concept are represented in the Table 5.

The self-concept of adolescents from foster families is characterized by a fairly positive assessment in terms of emotional well-being. At an ascertaining stage, most adolescents are satisfied with their appearance, have an adequate level of self-esteem, often express a realistic attitude to life situations and self-confidence.

At the same time, about a third of the subjects have manifestations of anxiety, a feeling of dissatisfaction with life, manifestations of both self-doubt and excessive self-confidence, which most often has a compensatorydefensive nature. These adolescents need psychological assistance.

At the control stage, adolescents from foster families began to assess highly their own emotional well-being, became more realistic about life situations and felt satisfied with life. They became more critical about their abilities and felt more confident in many situations.

The results of the analysis of the self-concept evaluation component are given in Table 6.

Table 6. Group indicators of self-assessment of the personal characteristics of foster adolescents at the ascertaining and control stages of the experiment (points obtained).

\begin{tabular}{lcccc}
\hline & \multicolumn{2}{c}{ Self-esteem } & \multicolumn{2}{c}{ Assertion } \\
\hline Personal characteristics & Ascertaining stage & Control stage & Ascertaining stage & Control stage \\
\hline Health & 60.2 & 65 & 91.4 & 86.1 \\
Character & $46.4^{*}$ & $54.9^{*}$ & 84 & 85.1 \\
Intelligence & 56.2 & 62.8 & 90.9 & 85.3 \\
Appearance & 64.5 & 68.1 & 81.2 & 82 \\
Self-confidence & $64.3^{*}$ & $72.8^{*}$ & 80.3 & 83.4 \\
Leader in a family & 69.2 & 73.2 & $77.7^{*}$ & $86.3^{*}$ \\
Leader in a class & 61.9 & 67.5 & 83 & 84.4 \\
\hline
\end{tabular}

Notes: : variation with $p \leq .05$.

In general, adolescents from foster families are characterized by realistic (adequate) self-esteem, with a tendency to high self-esteem. At the ascertaining stage of the experiment self-assessments only in the categories of Character and Intelligence correspond to the average level to. At the control stage, a shift towards increased self-esteem of adolescents was identified for all studied indicators, the largest statistically significant differences were found on the scales of "Character" and "Self-confidence". However, at the final stage of the experiment, the average level of self-esteem in the "Character" category did not change.

It is important to note that the assertion of foster adolescents at all stages of the experiment correspond to the most appropriate realistic level - which is high, with the exception of the Health and Intelligence indicators at the ascertaining stage. According to these indicators, adolescents treat their own abilities unrealistically and uncritically, which is characterized by importance they place on good health and a "brilliant" mind. At the control stage, the situation stabilized, and all indicators showcased positive dynamics, corresponding to the most realistic level. Statistically significant differences were found for the "Leader in the family" characteristic. 
The biggest discrepancy between self-esteem and assertion at the ascertaining stage was revealed in the categories Health, Character and Intelligence. Such a gap indicates a conflict between what the adolescent seeks and what he considers possible for himself. At the control stage, the discrepancy between self-esteem and assertion got back on track for all categories was optimized.

Indicators of the behavioural component of the self-concept of foster adolescents are summarized in Table 7.

Table 7. Indicators of the behavioural component of the self-concept of foster adolescents at the ascertaining and control stages of the experiment (\%).

\begin{tabular}{|c|c|c|c|}
\hline Scales & Scale levels & Ascertaining stage & Control stage \\
\hline \multirow{3}{*}{ Behaviour } & Inconsistent with adults' requirements & 42.3 & 30.8 \\
\hline & Realistic attitude & 42.3 & 53.8 \\
\hline & Consistent with adults' requirements & 15.4 & 15.4 \\
\hline \multirow{3}{*}{ Situation at school } & Rated as unfavourable & 46.3 & 42.3 \\
\hline & Neutral attitude & 38.3 & 42.3 \\
\hline & Positive perception & 15.4 & 15.4 \\
\hline \multirow{3}{*}{$\begin{array}{l}\text { Interpersonal } \\
\text { communication }\end{array}$} & Rated low & 0 & 0 \\
\hline & Rated moderate & 61.6 & 46.2 \\
\hline & Rated high & 38.4 & 53.8 \\
\hline \multirow{3}{*}{ Position in the family ${ }^{* *}$} & Unsatisfying & 38.4 & 7.8 \\
\hline & Satisfying & 38.4 & 61.3 \\
\hline & Highly satisfying & 23.2 & 30.9 \\
\hline
\end{tabular}

Notes: ${ }^{*}$ - variation with $p \leq .05,{ }^{* *}$ - variation with $p \leq .01$.

At an ascertaining stage, $42.3 \%$ of adolescents describe their behaviour as inconsistent with adults' requirements with a tendency to a negative attitude towards requirements, $46.3 \%$ of adolescents assess the school situation as unfavourable, which results in boredom, anxiety and loathing. At the same time, they experience sufficient satisfaction in the field of communication with peers and positively assess their popularity among them.

Adolescents are generally satisfied with the situation in the family. At the same time, $38.4 \%$ of the subjects are not satisfied with their position in the family; this position can be considered as a risk factor.

After the provision of the psychological and pedagogical conditions for the formation of the self-concept in adolescents from foster families, there has been observed a positive dynamic in the development of behavioural component of the self-concept.

The largest statistically significant differences were found in the values of the assessment of the ability to communicate, corresponding to a high level of satisfaction (by 15.4\%).

It is especially important to emphasize a significant change in the self-esteem of foster adolescents in terms of the degree of satisfaction with their position in the family (the shift in the moderate level of satisfaction was $22.9 \%$ and for the high level of satisfaction it increased for $7.7 \%$ ). 


\section{DISCUSSION AND CONCLUSION}

The review of psychological and pedagogical literature allows us to acknowledge the absence of special studies on the problem of forming a positive self-concept in adolescents from foster families.

The results of the ascertaining experiment indicate that foster adolescents have sufficient self-awareness, the ability to reflect, which is confirmed by the data obtained by other researchers (Gutkina, 1983; Vladimirova, 2007). Adolescents highly appreciate their communication skills interacting with peers and satisfaction with their position among peers, which is confirmed by N.A. Vikdorova's (2016) study. They quite positively assess their own emotional well-being (the results do not coincide with the position of O.A. Skorlupina (2015)).

At the same time, they experience a number of problems, namely: 1) difficulty in choosing a model of behaviour, especially in a foster family, because they do not know how family relations should be built; 2) excessive sensitivity to others evaluating or gauging their personalities, while it is important for them to call attention to themselves, to be recognized and needed. Adolescents from foster families express conflicting relationships with others with a predominance of conformal attitudes, congruency in contacts with others, on the one hand, and upholding their own point of view, a tendency toward leadership and dominance, on the other hand; 3) an unrealistic attitude to the state of one's health and to the possibilities of their intellectual self-fulfilment; 4) about half of the subjects believe that their behaviour is not normal, and they often show a negative attitude towards the requirements of adults, and also assess the school situation as unfavourable; 5) many of them (38.5\%) feel dissatisfaction with their life situation and their position in a foster family, there are features of future-phobia, which is probably why teenagers rarely think about the future and even less often talk about their future prospects.

The structural features of the self-concept of adolescents from a foster family were taken into account and made it possible to determine the main vectors of psychological and pedagogical approaches in addressing challenges of the positive self-concept formation.

According to the analysis of the control stage indicators, we can distinguish the following positive changes in the self-concept of foster adolescents: a rather high degree of self-actualization, self-attitude and ability to reflect, a tendency to self-acceptance as a holistic and consistent image of their "self", consistent with the ideal-self modality; a more adequate attitude to their capabilities, the dominance of the desire to establish collaborative relationships with others; manifestations of perseverance, self-confidence in many situations, reducing conformal attitudes; readiness for a constructive solution of conflict situations and efficient management of stressful conditions; a more realistic attitude to life situations and a feeling of satisfaction with life, as well as increasing satisfaction with their position in the family.

In recent years, in our country, foster families have increasingly become an alternative to institutional education in state institutions for orphans and children left without parental care. Specific conditions contributing to self-awareness, self-cognition, self-actualization and self-acceptance are needed for a more successful adaptation of a child in a foster family, for creation of psychological comfort, strengthening parentchild relationships and personality development.

The process of the self-concept formation is extremely long and complicated. According to the results of the forming experiment, the emerging trend towards adequacy in self-assessing adolescents' personal qualities, character traits, the concepts of real-self and ideal-self, towards decrease of internal conflicts, observation of 
moral standards confirm the effectiveness of the developed psychological and pedagogical conditions for the formation of a positive self-concept of foster adolescents in the aggregate of its cognitive, emotionalevaluative and behavioural components, as well as relevance and necessity of conducting such work.

\section{Limitation and study forward}

We recognize that the results of the study reflect a generalized picture of the formation of the self-concept of adolescents from foster families. The specificity of working with foster families contributes to a small number of the selected subjects. We intend to continue our research and identify the dynamics of the formation of a positive self-concept of adolescents brought up in foster families.

Further scientific research on this problem can evolve in following promising areas: the development of methodological foundations and search for new areas of psychological and pedagogical approaches to form a positive self-concept of adolescents, the development of formative programs for every stage of the adolescents development, as well as for other age groups' children from foster families.

\section{ACKNOWLEDGMENTS}

The work is performed according to the Russian Government Program of Competitive Growth of Kazan Federal University.

\section{REFERENCES}

Ananyev, B. G. (1980). Selected psychological works. Moscow: Pedagogika.

Avdeev, V.A., Avdeeva, O.A., Shagieva, R.V., Smirnova, V.V., Mashkin, N.A., \& Taradonov, S.V. (2019).

The mechanism of legal regulation in the conditions of globalization and formation of information environment. Regional aspect. Journal of Environmental Management and Tourism, 10(7), 1517152.

Bagandova, G. Kh. (2011). Causal Attribution of Adolescents Achievements Brought Up Outside the Family: PhD Thesis. Yaroslavl.

Barber, J. G., \& Delfabbro, P. H. (2003). Placement Stability and the Psychosocial Well-being of Children in Foster Care. Research on Social Work Practice, 13(4), 415-431. https://doi.org/10.1177/1049731503013004001

Bayanova, A.R., Vodenko, K.V., Sizova, Zh.M., Chistyakov, A.A., Prokopiev, A.I., \& Vasbieva, D.G. (2019). A philosophical view of organizational culture in contemporary universities. European Journal of Science and Theology, 15(3), 121-131.

Biktagirova, G. F., \& Valeeva, R. A. (2016). Study of Family Values of Adolescents from Families with Many Children Formation. Mathematics Education, 11(6), 1919-1926. https://doi.org/10.29333/iejme

Bogatyreva, T. L. (2008). The Development of Self-Concept of Early Adolescents Through Training: PhD Thesis. St. Petersburg.

Bolshakova, L. N. (2004). Socio-Psychological Adaptation of Parents and Children in a Foster Family: $\mathrm{PhD}$ thesis abstract. Yaroslavl.

Bozhovich, L. I. (2008). Personality and its formation in childhood. St. Petersburg: Piter.

Burns, R. B. (1982). Self-Concept Development and Education. London: Holt, Rinehart and Winston.

Butaryeva, T. S. (2019). Psychological and Pedagogical Features of the Self-Concept Formation in Early Adulthood. Modern Education: Current Issues, Achievements, and Innovations: Collected Papers of the 33rd International Research and Practice Conference, pp. 298-300.

Cohn, I. S. (1984). In Search of Self: Personality and Self-Identity. Moscow: Politizdat. 
Gimaliev, V.G., Prokopyev, A.I., Vershinin, V.P., Ivanova, M.E., Erkibaeva, G.G., Aytuganova, J.I., \& Alexandrova, N.S. (2020). Public Relations in Organizations in Student View: Accumulator of Management Tools or Formation of Partnership and Friendly Relations. Journal of environmental treatment techniques, 8(4), 1326-1330. https://doi.org/10.47277/JETT/8(4)1230

Gutkina, N. I. (1983). Personality Reflection in Adolescence: PhD thesis abstract. Moscow.

Healy, C., Coughlan, H., Williams, J., Kelleher, I., \& Cannon, M. (2019). Changes in self-concept and risk of psychotic experiences in adolescence: a longitudinal population-based cohort study. Journal of Child Psychology and Psychiatry and Allied Disciplines, 60(11), 1164-1173. https://doi.org/10.1111/jcpp.13022

Ivashchenko, A. V., Agapov, V. S., \& Baryshnikova, I. V. (2000). Methods of Personality Self-concept Study. Moscow: MGSA.

Jhang, F.-H. (2019). Life satisfaction trajectories of junior high school students in poverty: Exploring the role of self-efficacy and social support. Journal of Adolescence, 75, 85-97. https://doi.org/10.1016/i.adolescence-.2019.07.011

Khairullina, E.R., Shubovich, M.M., Bogdanova, V.I., Slepneva, E.V., Mashkin, N.A., \& Rodyukova, T.N. (2020). Modern student youth civic identity: Political activity or social responsibility? Opcion, 36(Special Edition 27), 1703-1717.

Kozina, A. (2019). The Development of Multiple Domains of Self-Concept in Late Childhood and in Early Adolescence. Current Psychology, 38(6), 1435-1442. https://doi.org/10.1007/s12144-017-9690-9

Oswald, S. H., Heil, K., \& Goldbeck L. (2009). History of Maltreatment and Mental Health Problems in Foster Children. Journal of Pediatric Psychology, 35(5), 462-472. https://doi.org/10.1093/ipepsy/jsp114

Ovsyanikova, E. A. (2018). Self-Concept of the Adolescents' Personality Brought Up in Native and Foster Families. Bulletin of the Belgorod Institute for the Development of Education, 2(8), 73-83.

Piralova, O.F., Gerasimenko, S.A., Kuznetsov, V.V., Popova, O.V., Subbotin, G.V., Kolomyts, O.G., \& Mashkin N.A. (2020). Gaming Industry Trends in new Generation Specialist Training in University Environment. Journal of Environmental Treatment Techniques, 8(3), 1132-1135.

Podymov, N.A., Nikoghosyan, M.A., Stolyarova, A.N., Narutto, S.V., Mashkin, N.A., Martynenko, S.E., Paznikova, Z.I., \& Varenik, P.K. (2019). University New Educational Reality in Disruptive Technologies Context. Journal of Environmental Treatment Techniques, 7(4), 664-668.

Prikhozhan, A. M., \& Tolstoy, N. N. (2007). Psychology of Orphanhood. St. Petersburg: Piter.

Prokofieva, E.N., Erdyneyeva, K.G., Galushkin, A.A., Prokopyev, A.I., Prasolov, V.I., Ashmarina, S.I., Ilkevich B., \& Kubiatko, M. (2018). Risk based ecological economics to engineering students. Eurasia Journal of Mathematics, Science and Technology Education, 14(3), 753-764. https://doi.org/10.12973/ejmste/80903

Rassolov, I.M., Chubukova. S.G., Mokhov, A.A., \& Shagieva, R.V. (2020). Genetic information and personal data under conditions of digital transformation. International Journal of Psychosocial Rehabilitation, 24(7), 284-292.

Rean, A. A., Bordovskaya, N. V., \& Rozum, S. I. (2002). Psychology and Pedagogy. St. Petersburg: Piter. Remschmidt, H. (1994). Prepubescence and Adolescence: Problems of Personality Development. Moscow: Mir.

Rogers, C. R. (1961). On Becoming a Person: A Therapist's View of Psychotherapy. Moscow: Progress. Skorlupina, O. A. (2015). The Psychological Health of Adolescents from Foster Families. Psikhologicheskoye zdorov'ye i psikhologicheskaya kul'tura $\mathrm{v}$ sovremennom rossiyskom obrazovanii: materialy VI vserossiyskoy nauchno-prakticheskoy konferentsii - Psychological Health and Psychological Culture in Modern Russian Education: Proceedings of the 6th All-Russian Research and Practice Conference, 169-171. 
Sventsitsky, A. L. (2008). Concise Psychological Dictionary. Moscow: Prospect.

Svistunova, E. V. (2002). Features of Self-Concept of Adolescent with Impaired Behavior: PhD Thesis. Moscow.

Vikdorova, N. A. (2016). Features of the Content Characteristics of the Sovereignty of Adolescents Brought Up in Foster Families. Multidisciplinary Internet Scientific Journal of the Kuban State Agrarian University, 124, 71-78. https://doi.org/10.21515/1990-4665-124-045

Vladimirova, Yu. N. (2007). The Development of the Self-Concept of a Younger Teenager (11-12 years). Psikhologicheskaya nauka i obrazovaniye - Psychological Science and Education, 5(12), 127-137. 